\title{
UMA RELEITURA DA PRÁTICA PEDAGÓGICA POR MEIO DE RELATOS DE DOCENTES ATUANTES NOS ANOS INICIAIS
}

\author{
Karine Lôbo Castelano* \\ Eliana Crispim França Luquetti**
}

\begin{abstract}
Resumo: Este estudo tem o propósito de discutir a respeito das práticas de leitura e escrita de duas professoras do $2^{\circ}$ ano do Ensino Fundamental I de escolas públicas de Campos dos Goytacazes/RJ. Para tanto, a metodologia utilizada nesta pesquisa é de abordagem qualitativa, descritiva e exploratória, uma vez que pretende descrever, analisar e interpretar questões emergentes dessa relação entre leitura e escrita (GIL, 2010). Percebemos que as docentes participantes desta pesquisa precisam abordar teorias estabelecendo uma ponte com a prática pedagógica. É importante que elas tenham consciência da necessidade de dominar determinados conhecimentos teóricos para tomar decisões fundamentadas no que diz respeito ao processo de inclusão e participação do aluno no mundo da leitura e da escrita.
\end{abstract}

Palavras-chave: Prática educacional. Leitura. Escrita. Formação de professores. Educação linguística.

\begin{abstract}
This study aims at discussing the practices of reading and writing of two teachers of the 2 nd year of elementary school in the public schools of Goytacazes/ RJ. Therefore, the methodology used in this research is qualitative, descriptive and exploratory, as it intends to describe, analyze and interpret emerging issues in this respect (GIL, 2010). We noticed that the teachers participating in this research need to address theories, establishing a bridge with pedagogical practice. It is important that they be aware of the need to master certain theoretical knowledge to make informed decisions with regard to the inclusion and the participation of the student in the world of reading and writing.
\end{abstract}

Keywords: Educational practice. Reading. Writing. Teacher training. Language education.

\section{Introdução}

A busca pela melhoria da qualidade da educação é uma meta constante nas academias. Para isso, percebemos a necessidade de uma compreensão ampla da educação, da escola e de suas finalidades, bem como do desenvolvimento dos processos de ensinoaprendizagem e a forma como estes promovem o desejo de aprender dos alunos, construindo, assim, um ser crítico e reflexivo em relação ao conhecimento. Seguindo essa perspectiva, os cursos de licenciatura buscam formar profissionais conhecedores de sua área de atuação, preparando-os para enfrentar os percalços da realidade escolar e também capacitá-los a construir um conhecimento pedagógico consistente dotado de significado de acordo com o contexto.

Entretanto, percebemos que a prática educacional é alvo constante de discussões que determinaram seu desenvolvimento em diversos aspectos, especialmente no que se refere às metodologias de ensino utilizadas pelos educadores e a valorização do contexto escolar para a formação dos alunos.

Diante do exposto, convém ressaltar que este estudo tem o propósito de discutir, por meio da aplicação de um questionário estruturado, a respeito das práticas de leitura e escrita de duas professoras da educação infantil. Seguimos um viés baseado em Alves (2003), Soares (2004, 2006), Bagno (2002), dentre outros autores, que buscam fazer uma reflexão a respeito, principalmente, da prática pedagógica de duas docentes do $2^{\circ}$ ano do Ensino Fundamental I de escolas públicas de Campos dos Goytacazes/RJ.

\footnotetext{
* Doutoranda em Cognição e Linguagem, Universidade Estadual do Norte Fluminense Darcy Ribeiro. Endereço eletrônico: kcastelano@yahoo.com.br .

** Doutora em Linguística, professora associada da Universidade Estadual do Norte Fluminense Darcy Ribeiro. Endereço eletrônico: elinafff@gmail.com .
} 
Este trabalho possui mais quatro seções principais. No item seguinte, por meio de uma revisão teórica, será apresentada uma breve reflexão teórica a respeito do papel da escola no desenvolvimento da leitura e da escrita, além da importância da formação continuada para a atuação em sala de aula. Em seguida, tem-se a metodologia empregada. Por fim, é apresentada a discussão e interpretação da análise dos dados, bem como algumas considerações finais.

\section{O papel da escola no desenvolvimento da leitura e da escrita}

O processo de aquisição da linguagem começa ainda no ventre materno, uma vez que é ali que o bebê tem seus primeiros contatos com os sons que possivelmente se tornarão sua língua materna. De acordo com Vygotsky (2001), longe de explicitar uma reflexão previamente construída é o engajamento em argumentação que possibilitará o desenvolvimento da reflexão, ou seja, o processo cognitivo e a capacidade de argumentação tem início muito antes do processo de alfabetização. No que diz respeito ao ensino da língua materna, Neves (1997) afirma que

[...] a aquisição da linguagem se desenvolve na interação comunicativa entre a criança e seu ambiente; aos fatores genéticos se atribuem apenas aqueles princípios subjacentes que não podem explicar-se por essa interação. $\mathrm{O}$ processo de aquisição da linguagem é fortemente codeterminado por um "input" altamente estruturado de dados linguísticos, apresentados à criança em contextos naturais e adaptados ao nível de sua competência comunicativa (NEVES, 1997, p. 45).

Mesmo antes de se tornar alfabetizado, o indivíduo é um ser pensante, capaz de refletir. Logo, a alfabetização e o letramento deveriam ser uma forma de auxílio e melhoramento na capacidade de se expressar do indivíduo, e não um agente opressor, caracterizando o não alfabetizado como incapaz.

A alfabetização, em seu sentido restrito, tem como fundamento o aprendizado do alfabeto e da utilização deste como código de comunicação. No processo de aprendizagem da leitura, a competência de decodificar os sinais gráficos faz surgir os primeiros sons produzidos conscientemente pelos leitores iniciantes; já na escrita, a competência de codificar os sons da língua auxilia na construção dos sinais gráficos, criando os primeiros registros do indivíduo, que se reconhece agora como alfabetizado.

Entretanto, ao longo dos anos, a ideia de alfabetização foi sendo ampliada devido às constantes mudanças da sociedade, ao processo de globalização e velocidade de troca de informação, exigindo que o conhecimento do indivíduo não se restrinja apenas ao domínio das habilidades de codificação e decodificação; mas sim que ele amplie sua capacidade de interpretar, criticar, compreender e gerar conhecimento para assim estar de fato integrado à sociedade.

A partir desse novo conceito de alfabetização, surgiu o termo letramento, que serve para indicar o conjunto de conhecimentos, atitudes e capacidades necessárias para usar a língua em práticas sociais. Tem-se no letramento a ampliação do significado de alfabetização, pois, além de saber ler e escrever, é de fundamental importância que o indivíduo agora faça uso frequente da leitura e da escrita de forma crítica, demonstrando que houve, de fato, a aprendizagem das mesmas.

De acordo com Soares (2006, p. 3), letramento é o “[...] estado ou condição de quem não só sabe ler e escrever, mas exerce as práticas sociais de leitura e de escrita que circulam na sociedade em que vive, conjugando-as com as práticas sociais de interação oral”. A mesma 
autora, em seu livro Letramento: um tema em três gêneros, considera que as definições para letramento distinguem-se e entram em contradição por cada uma basear-se em determinada dimensão de letramento. Essa dificuldade existe por causa da extensão e variedade das capacidades individuais que podem ser determinadas como constituintes do letramento (SOARES, 2004). Segundo a pesquisadora, separar a alfabetização e o letramento é um erro, já que a entrada da criança e do adulto não alfabetizado no mundo da escrita se dá, ao mesmo tempo, pelos dois processos. Trata-se de processos "interdependentes" e "indissociáveis". Portanto, a alfabetização acontece por meio de práticas sociais de leitura e escrita, ou seja, por meio de atividades de letramento, que, por sua vez, só pode desenvolver-se juntamente com a alfabetização.

Algumas orientações fundamentadas no conceito de letramento valorizam, de forma parcial, importantes conquistas como o prazer de ler e escrever e a inclusão nas práticas sociais da leitura e da escrita. Sendo assim, entende-se alfabetização como um processo indispensável de adaptação do sistema de escrita que possibilita ao indivíduo ler e escrever com autonomia. Em relação ao letramento, este trata do processo de inclusão e participação no mundo da escrita. Soares $(2004$, p. 18) afirma que "[...] nosso problema não é apenas ensinar a ler e a escrever, mas é também e, sobretudo, levar os indivíduos - crianças e adultos - a fazer uso da leitura e da escrita, envolver-se em práticas sociais de leitura e de escrita".

Alves (2003) afirma que, a depender do tratamento dado às questões ortográficas e fonológicas no início do processo de alfabetização, muitas dificuldades poderão ser evitadas e compete ao alfabetizador criar situações que possibilitem ao aluno fazer uso da lingua(gem) escrita como forma de expressão e comunicação, logo, como bem social a que ele tem direito.

Levando-se em conta que os alunos que estão sendo alfabetizados vivem em uma sociedade letrada onde a língua escrita encontra-se efetivamente presente nas atividades do dia a dia, há grande possibilidade de esses indivíduos terem acesso a textos escritos, tirando suas próprias conclusões a respeito da sua utilidade na sociedade. A exclusão dessa vivência em sala de aula tanto pode reduzir e tornar artificial o objeto de aprendizagem, a escrita, quanto pode deixar de explorar a relação que os alunos têm fora da sala de aula com a mesma.

\section{A importância da formação continuada para a atuação em sala de aula}

A questão da leitura e da escrita é, sem dúvida, um dos aspectos mais importantes na formação do professor, pois são eles que interferem nas relações em sala de aula e na qualidade de assimilação do conhecimento que nela ocorre.

Por isso, é imprescindível que nos cursos de formação de professor se coloquem em debate essa questão. Tanto a leitura quanto a escrita são fundamentais na atuação do professor que exerce um papel mediador na produção de conhecimentos. Além disso, a função social da escola é inquestionável. Corroborando essas ideias, Soares (2006, p. 5) enfatiza "[...] o fracasso escolar dos alunos pertencentes às camadas populares, comprovado pelos altos índices de repetência e evasão, mostra que, se vem ocorrendo uma progressiva democratização do acesso à escola, não tem igualmente ocorrido a democratização da escola".

Apesar disso, sabemos que é na escola que se dá e se amplia a competência comunicativa dos indivíduos, como meio de ascensão social e da necessidade de se apropriar da língua dita "culta", sem perder de vista as perspectivas político-ideológicas envolvidas. Precisamos resgatar o respeito do professor pelos "falares" do aluno e, consequentemente, de sua cultura, o que possibilita ao sujeito manter seu autorrespeito e conscientização do valor expressivo. Além disso, a discriminação de sua variedade linguística pode prejudicar seu desenvolvimento psicossocial e gerar conflitos que dificultem ainda mais a necessária 
ampliação e diversificação de sua competência comunicativa objetivada por sua escolarização. Segundo Guedes (2006),

[...] o professor não é um leitor como qualquer outro: ele precisa aprender como se aprende a ler para descobrir como se ensina a ler e não tem outro jeito a não ser observar-se aprendendo a ler. Esse aprendizado baseia-se em sua leitura pessoal, indispensável para ensinar a ler, mas insuficiente se não for uma leitura feita em confronto com a leitura da tradição (GUEDES, 2006, p. 64).

O professor deve ter consciência de que, abrindo novas perspectivas de interação na escola, ele possibilitará novas formas de interação com a sociedade. Sendo assim, o professorpedagogo, usando tal premissa como norteadora de seu trabalho docente, poderá criar espaços e estratégias mais adequados de comunicação na sala de aula. Ao respeitar e valorizar os conhecimentos prévios de seus educandos, o professor permitirá a eles desenvolver seu senso crítico de acordo com a realidade em que vivem e, posteriormente, ampliando essa capacidade para todas as possíveis situações de seu cotidiano.

\section{Metodologia}

A metodologia utilizada nesta pesquisa é de abordagem qualitativa e, como instrumento de coleta de dados, foi aplicado um questionário de caráter exploratório a duas docentes do $2^{\circ}$ ano do Ensino Fundamental I de escolas públicas de Campos dos Goytacazes/RJ. Nosso objetivo era coletar dados a respeito da prática pedagógica dessas profissionais e verificar como o ensino da língua materna está sendo desenvolvido em sala de aula, mais especificamente no que diz respeito à escrita, à leitura e à expressão oral do alunado. Trata-se de uma pesquisa descritiva e exploratória, uma vez que pretende descrever, analisar e interpretar questões emergentes desta relação (GIL, 2010).

A docente 1 tem formação em Letras com habilitação em Língua Portuguesa e Literatura e possui experiência com alunos do Ensino Fundamental I há vinte anos. Por sua vez, a docente 2 tem formação no curso de Normal Superior e possui experiência de quinze anos com alunos, também, do Ensino Fundamental I.

Ambas têm especialização em Psicopedagogia há mais de dez anos. Além disso, trabalham em escolas municipais de Campos dos Goytacazes/RJ e participam de um projeto de extensão promovido pela Universidade Estadual do Norte Fluminense Darcy Ribeiro.

No item a seguir, apresentaremos a análise e interpretação dos dados coletados.

\section{A educação linguística no processo de alfabetização: o que pensam os professores?}

No que se refere ao fato de como as professoras acreditam que deva ser o início do processo de alfabetização, a docente 1 afirmou que cada professor precisa seguir uma linha de pensamento e técnicas de alfabetização. Mesmo trabalhando com crianças do ensino fundamental, ela considera que a alfabetização deve ser iniciada pela base menor, ou seja, a letra, e, a partir dela, formar palavras e produzir textos.

Diferentemente da primeira docente, a docente 2 acredita que o processo de alfabetização deve começar pela análise da palavra contextualizada numa frase, ou num texto, mas o principal é levar em consideração a realidade daquele determinado contexto escolar, pois cada turma em cada escola possui suas particularidades e dificuldades. Para ela, o professor precisa apresentar aos alunos textos variados e estimulantes e deles analisar palavras 
significativas, estudar os fonemas que a compõem e relacioná-los a outras palavras, ampliando assim seu vocabulário. Além disso, é preciso voltar ao texto a fim de que o aluno entenda que os morfemas e as desinências não existem dissociadas de significado, elas registram a intenção de comunicação das diversas formas de texto, como bulas de remédio, poesias, cardápios de restaurante, entre outros. Em outras palavras, a alfabetização acontece inserindo o aluno no mundo letrado.

Entretanto, diferente das docentes questionadas, não acreditamos que o processo de alfabetização dos alunos precise seguir a ordem das letras do alfabeto ou as famílias silábicas. Para nós, a escrita não é silábica, mas alfabética. Além disso, a linguagem deveria ser estudada e discutida em uso, e não em situações artificiais, assim como afirmam Bagno (2002), Alves (2003) e Soares (2004).

Ao chegar à escola, os alunos já têm suas próprias hipóteses sobre a escrita e a leitura, pois convivem com elas há algum tempo, ainda que de forma assistemática (VYGOTSKY, 1988). Observamos que, de acordo com as docentes questionadas para esta pesquisa, o alfabeto é apresentado desde o início do processo de alfabetização. A docente 2 trabalha com textos que circulam socialmente e mostram a língua com seus múltiplos sentidos nos diferentes contextos em que é usada. Os alunos são solicitados a estar em contato constante e escrever textos diversos (curtos, longos, de vários gêneros, indicativos de diferentes contextos), diferente do método utilizado pela docente 1. De acordo com Marcuschi (2001), esta metodologia deveria ser aplicada em todas as escolas brasileiras.

Quanto ao ensino da leitura e da escrita, a docente 1 relatou que esses dois itens estão estreitamente ligados. A partir do momento que ela propõe uma atividade de produção textual, por exemplo, espera que seu aluno leia outros textos ou busque informações para argumentar em sua produção. É sabido que os textos retirados de diferentes fontes têm seus suportes preservados na medida do possível, pois se sabe que as crianças necessitam ter acesso às mídias e aos contextos diversos de utilização da língua para compreender seus variados usos, e também que a língua deve ser entendida no movimento da negociação de sentidos que ocorre num determinado contex to histórico-cultural. Entretanto, é imprescindível que a professora exerça seu papel de mediadora e direcione seus alunos para que eles busquem por textos que realmente tenham ligação com o que foi ensinado em sala de aula.

Corroborando as experiências da docente 1, a docente 2 acrescenta que não se pode separar escrita e leitura, pois a escrita depende da leitura e vice-versa, mesmo antes de entrar na escola, a criança já realiza a leitura de rótulos, capas de revistas, etiquetas, etc., uma leitura logográfica. Portanto, na escola, não se pode abandonar esta habilidade adquirida e o ensino da leitura e da escrita deve acontecer concomitantemente. Para ela, a leitura dá-se a partir do estudo da palavra, relacionando fonemas e grafemas. Realizando esta relação, a criança é capaz de aprender a ler várias palavras relacionadas aos fonemas explorados de maneira natural e os resultados são excelentes.

Consideramos que a produção de textos da escola como fruto do trabalho conjunto entre professor e alunos, envolvendo compreensão e interpretação de textos escritos e orais de gêneros diversos, assim como a intencionalidade, a situação e o interlocutor. Para o processo desse trabalho, é fundamental que o professor tenha clareza das funções sociais, condições e processos de produção de textos, assim como acreditam as docentes participantes desta pesquisa.

As docentes participantes desta pesquisa propõem certas atividades de oralidade, assim como sugere Bagno (2002). Elas sabem que o uso da linguagem ocorre diariamente, e não só nas aulas de português ou na escola. Com a interferência do professor, que orientará a conversa - solicitando argumentos ou explicitando-os se não estiverem claros, estimulando hipóteses ou conclusões sobre determinados assuntos, apontando ambiguidades - , os alunos irão constituindo modelos de falas e assimilando atitudes, como esperar a vez de falar ou 
simplesmente ouvir com atenção uma história ou uma explicação. As atividades também contemplam a percepção e discussão das semelhanças e diferenças entre a língua oral e a escrita, assim como o reconhecimento de aspectos ligados à oralidade como o gesto, a postura, a entoação e a dicção.

Em relação à valorização da variedade linguística do aluno, para a docente 1, estimular a expressão oral dos alunos é necessário para que ela possa conhecer as dificuldades de se expressar de cada aluno, bem como as diferenças linguísticas de cada um. Cada aluno tem uma bagagem cultural adquirida ao longo de sua vida, e que deve ser respeitada e orientada pelo professor. A escola deve respeitar os diferentes usos que se faz de uma língua, mas, paralelamente, fazer o trabalho de apresentação e inserção da linguagem padrão, a fim de que ele possa utilizá-la em qualquer situação de leitura ou escrita que surja para o mesmo enquanto leitor. Percebemos que, apesar da docente falar que a variedade linguística deve ser respeitada, ao finalizar seu texto, ela diz que deve ensinar a linguagem padrão para que o aluno saiba utilizá-la apenas para a leitura e a escrita. Mas, sabemos da importância do aluno saber utilizar a linguagem oral nas diferentes situações comunicativas, principalmente, nas formais, como em entrevistas e seminários.

A docente 2, em sua prática, realiza diariamente o exercício da expressão oral nas "rodinhas de conversa". De acordo com ela, nesses momentos, "o estímulo para o diálogo pode vir de uma história, do relato de uma situação vivida ou mesmo da conclusão de um tema abordado em aula". Ela diz estimular a expressão oral dos mais tímidos e, com isso, "perceber as características linguísticas de cada aluno", sem corrigir o que é certo ou errado, apenas apontando as diferenças existentes na língua. Essa fala mostra que a professora não retrata a linguagem oral com preconceito, assim como recomendam Bagno $(2002,2004)$ e Soares $(2004,2006)$. Entretanto, não comentou a respeito de como utiliza esse recurso para mostrar tais características para seus discentes.

Embora, ao entrar na escola, a criança já seja falante da língua materna; nas aulas, ela deve aprimorar sua expressão oral no que se refere à clareza, fluência, entoação, entre outros fatores. É preciso ter consciência de que a intenção não é fazer com que a fala dos alunos reproduza a modalidade escrita (esta é uma das concepções equivocadas que cercam o trabalho da oralidade), também não é uniformizar a fala de todos eles, pois isso seria outro equívoco, já que a língua é viva e possui idiossincrasias. Contudo, a língua oral possui variedades que devem ser evitadas, dependendo do contexto, como já foi dito.

Quanto à ortografia, sabemos que os alunos precisam, desde cedo, compreender que a língua portuguesa escrita não é transcrição da fala e que há regras que determinam a maneira de grafar cada palavra. A ortografia foi criada para impedir a variação dialetal na escrita e facilitar sua compreensão (BAGNO, 2002; SOARES, 2004, 2006).

Escrever corretamente as palavras é importante e indispensável. Não é simplesmente dizendo à criança "pense como se escreve tal palavra" que a estaremos auxiliando no desenvolvimento desta atividade. Ela não irá descobrir a regra simplesmente pensando; existem normas e exceções a serem seguidas que o professor, como mediador do conhecimento, deve apresentar. Como a norma ortográfica é uma convenção social, a criança deve ser auxiliada em sua aprendizagem (NEVES, 1997).

No início do processo de alfabetização encontramos crianças que já escrevem, mas cometem erros de grafia, e outras que estão fazendo suas primeiras tentativas de escrita. As interferências do professor devem ser diferenciadas. É preciso fazer os alunos entenderem que alguns casos de grafia correta se aprendem por regras e outros, por memorização.

Questionamos as professoras sobre como explicar às crianças o porquê de lobo ser escrito com $o$ e pronunciado com $u$. A docente 1 afirma não se apegar apenas às regras de ortografia, pois eles estão em fase de aprendizagem, afirma deixar claro que existem diferenças entre a maneira de falar e de escrever e considera que com o tempo e o uso eles 
acabam aprendendo, sem necessidade de decorar todas as regras e exceções. Já a docente 2 explica que, a partir da análise das características da expressão oral dos próprios alunos em comparação com a escrita formal das palavras, o aluno vai descobrindo que muitas palavras são pronunciadas de uma forma particular que pode variar de pessoa, para pessoa, de região para região. A partir do estudo da linguagem formal o aluno vai percebendo essas diferenças, assimilando as regras da língua escrita.

Em relação ao ensino das regras de acentuação, como por exemplo, o acento gráfico da palavra bebê, a docente 2 informa que explica a regra ortográfica de acentuação das oxítonas terminadas em $e$, e, posteriormente, por meio de exercícios de fixação de comparação com outras palavras que apresentem a mesma regra, acredita que o aluno passa a assimilar a escrita da palavra. Dessa forma, ela propõe situações que desenvolvam as habilidades de observação, análise e memorização. Não queremos incentivar a memorização mecânica, mas desenvolver essa faculdade humana para que possa auxiliar no processo de aprendizagem da escrita, assim como sugere Bagno (2002).

A docente 1 não concorda em ensinar a regra de acentuação para seus educandos das séries iniciais. Ela explica o uso da acentuação apenas por meio de situações propostas de leitura e escrita. De acordo com Soares (2004), o melhor material para trabalhar a ortografia é a escrita das crianças.

No que diz respeito ao conhecimento sobre Fonética e Fonologia, teorias essenciais da Linguística que estudam os sons da fala e como eles são produzidos, ambas as docentes afirmaram tê-las estudado durante a graduação. Entretanto, percebemos que, apesar de seus conhecimentos, a docente 2 , ao responder o questionário, menciona a expressão "língua culta", ao invés de "língua padrão", como defende Bagno $(2002,2004)$.

\section{Considerações finais}

Este trabalho propôs discutir a respeito das práticas de leitura e escrita por meio da aplicação de um questionário estruturado, a duas professoras da educação infantil. Corroborando Neves (1997), acreditamos que seja preciso criar um ambiente propício para o processo de ensino-aprendizagem, fazendo não só com que cada aluno tenha estabelecido o seu direito de aprender a ler e a escrever, mas também participe do mundo da leitura e da escrita. Não se deve esperar, portanto, que desde o início da alfabetização todas as crianças estejam lendo e escrevendo da mesma forma. $\mathrm{O}$ professor deve ser visto como alguém que entende o erro como uma etapa da aprendizagem, estabelecendo-se, dessa forma, uma relação de confiança. A interação entre o professor e os alunos é fundamental nessa fase.

As dificuldades enfrentadas hoje na alfabetização são agravadas tanto pela herança do analfabetismo e das desigualdades sociais, quanto pela ampliação do conceito de alfabetização e das possibilidades da sociedade no que diz respeito a seus resultados. Portanto, se o professor não estiver preparado para as diversidades encontradas em sala de aula, terá grande probabilidade de levar os discentes pertencentes às camadas pobres da sociedade a terem um desempenho inadequado e, consequentemente, a acreditarem que são fracassados.

Nessa perspectiva, acreditamos que os professores precisam abordar teorias estabelecendo uma ponte com a prática pedagógica. É importante que eles tenham consciência da necessidade de dominar determinados conhecimentos teóricos para tomar decisões fundamentadas no que diz respeito ao processo de inclusão e participação do aluno no mundo da leitura e da escrita.

Infelizmente, em muitas escolas brasileiras, a didática utilizada pelos professores ainda não aborda e/ou trabalha nas salas de aula a extensa variedade linguística presente no 
cotidiano da sociedade, limitando-se a ensinar apenas a gramática tradicional, e considera como exceções o que esta não consegue explicar. Dessa forma, o aluno não é motivado a compreender diferentes usos que se pode fazer da fala, levando-o a acreditar que sua variedade linguística é errada ou pior que a apresentada pela professora.

Assim como as docentes participantes da pesquisa, nossa proposta é que os alunos possam comparar a língua escrita e língua oral, percebendo suas semelhanças, diferenças e contextos de uso de cada uma delas. A língua escrita é de natureza espacial, ocorrendo numa superfície, com caráter duradouro, enquanto a língua oral é de natureza temporal, tem apenas a duração da fala. Ao analisarem a modalidade oral usada por diferentes pessoas, os alunos aprenderão que há diversas formas de falar ou nomear objetos, alimentos, e que existem variações linguísticas e não erros. Para que haja essa mudança de pensamento, é preciso que o professor mantenha-se atualizado em relação às pesquisas linguísticas e que acredite que a educação linguística não é um produto final, mas um processo contínuo.

\section{Referências}

ALVES, M. F. Passos e descompassos da alfabetização. Goiânia: Editora da UFG, 2003.

BAGNO, M. A inevitável travessia: da prescrição gramatical à educação linguística. In: ; STUBBS, M.; GAGNÉ, G. Língua materna: letramento, variação e ensino. São Paulo: Parábola, 2002.

Preconceito linguístico: o que é, como se faz. $28^{\circ}$ ed. São Paulo: Ed. Loyola, 2004.

GIL, A. C. Como elaborar projetos de pesquisa. São Paulo: Atlas, 2010.

GUEDES, P. A formação do professor de português: que língua vamos ensinar? São Paulo: Parábola, 2006.

MARCUSCHI, L. A. Letramento e oralidade no contexto das práticas sociais e eventos comunicativos. In: SIGNORINI, I. (Org.). Investigando a relação oral/ escrito. Campinas: Mercado de Letras, 2001, p. 23-50.

NEVES, M. H. de M. A gramática funcional. São Paulo: Ed. Martins Fontes, 1997.

SOARES, M. Alfabetização e letramento. São Paulo: Contexto, 2005.

Letramento: um tema em três gêneros. Belo Horizonte: Autêntica/ CEALE, 2004.

Português: uma proposta para o letramento. São Paulo: Moderna, 2006.

VYGOTSKY, L. S. A pré-história da linguagem escrita. In: A formação social da mente. São Paulo: Martins Fontes, 1988.

. A construção do pensamento e da linguagem. São Paulo: Martins Fontes, 2001.

Recebido em: março de 2013.

Aprovado em: julho de 2013. 